\title{
ACTIVIDAD MODULADORA IN VITRO DE EXTRACTOS ACUOSOS DE PLANTAS AMERICANAS SOBRE LA TOXICIDAD INDUCIDA POR CLORPIRIFOS EN ESPLENOCITOS MURINOS
}

\author{
IN VITRO MODULATING ACTIVITY OF AQUEOUS EXTRACTS FROM AMERICAN PLANTS ON \\ CHLORPYRIFOS-INDUCED TOXICITY ON MURINE SPLENOCYTES
}

Ana V. Scotta ${ }^{1}$, Guillermina A. Bongiovanni², Elio A. Soria ${ }^{1,3}$.

\section{Resumen}

Antecedentes: Clorpirifos es un pesticida altamente tóxico, que puede producir inmunotoxicidad con efectos deletéreos sobre la salud a nivel mundial. Por otro lado, las plantas americanas pueden tener derivados con actividad protectora e inmunoestimulante. Por lo tanto, debe evaluarse el potencial de estas plantas frente a clorpirifos. Objetivo: Identificar extractos acuosos bioactivos de Lantana grisebachii (LG), Aspidosperma quebracho-blanco (AQ), Peumus boldus (PB), e Ilex paraguariensis (IP), contra la toxicidad de clorpirifos sobre esplenocitos de hembras Balb/c. Materiales y Métodos: Esplenocitos fueron tratados in vitro por 72 horas con $0-35 \mu \mathrm{g} / \mathrm{mL}$ de clorpirifos, $0-100 \mu \mathrm{g} / \mathrm{mL}$ de cada extracto (LG, $A Q, P B, I P)$ y $0-5$ $\mu \mathrm{g} / \mathrm{mL}$ de concanavalina A. Luego, se midió y analizó estadísticamente viabilidad y muerte celular (tinciones de resazurina y yoduro de propidio), hidroperóxidos, lipoperóxidos (ensayos basados en naranja de xilenol), actividad de la y-glutamiltranspeptidasa (método de Szasz). Resultados: Clorpirifos redujo la viabilidad celular de forma dosis dependiente, lo que fue contrarrestado por AQ e IP, los que fueron menos activos en las células inducibles por concanavalina $A(p<0,05)$. La toxicidad por clorpirifos implicó la inducción de la y-glutamiltranspeptidasa con la consecuente reducción de los peróxidos, mientras que $A Q$ y principalmente IP antagonizaron dichas respuestas $(p<0,05)$. Conclusiones: Los extractos de Ilex paraguariensis y Aspidosperma quebracho-blanco protegieron in vitro a los esplenocitos frente a clorpirifos. Este efecto dependió del tipo celular, dado que las células inducibles por concanavalina $A$ fueron más susceptibles a este tóxico.

Palabras clave: concanavalina A; fitoterapia; Ilex paraguariensis; linfocitos; oxidación-reducción; quebracho; té.

\section{Abstract}

Background: Chlorpyrifos is an highly toxic pesticide, which can induce immunotoxicity with deleterious effects on health worldwide. On the other hand, American plants can provide derivatives with protective and immunostimulating activity. Thus, plant potential against chlorpyrifos should be assayed. Objective: To identify bioactive aqueous extracts from Lantana grisebachii (LG), Aspidosperma quebracho-blanco (AQ), Peumus boldus (PB), and llex paraguariensis (IP), against chlorpyrifos-induced toxicity on female Balb/c splenocytes. Material and method: Splenocytes were treated in vitro for 72 hours with $0-35 \mu \mathrm{g} / \mathrm{mL}$ of chlorpyrifos, $0-100 \mu \mathrm{g} / \mathrm{mL}$ of each extract (LG, AQ, PB, IP), and $0-5 \mu \mathrm{g} / \mathrm{mL}$ of concanavalin A. Then, cellular viability and death (resazurin-based and propidium iodide stainings), hydroperoxides, lipoperoxides (xylenol orange-based assay), y-glutamyl transpeptidase activity (Szasz method) were measured and analyzed statistically. Results: Chlorpyrifos reduced splenocyte viability in a dose-dependent manner, which was counteracted by $A Q$ and IP, which was less active in concanavalin A-responsive cells $(p<0.05)$. Chlorpyrifos toxicity involved $\mathrm{y}$-glutamyltranspeptidase induction with a consequent peroxide reduction, whereas $A Q$ and mainly IP antagonized these responses $(p<0.05)$. Conclusions: The extracts of llex paraguariensis and Aspidosperma quebracho-blanco protected splenocytes in vitro against chlorpyrifos. This effect depended on cellular type, given that concanavalin A-responsive cells were more susceptible to this toxic.

Key words: concanavalin A; phytotherapy; Ilex paraguariensis; lymphocytes; oxidation-reduction; quebracho; tea.

\footnotetext{
1 Instituto de Investigaciones en Ciencias de la Salud (INICSA), Universidad Nacional de Córdoba - CONICET, calle Enrique Barros s/n, Córdoba 5014, Argentina.

2 Instituto de Investigación y Desarrollo en Ingeniería de Procesos, Biotecnología y Energías Alternativas (PROBIEN), Universidad Nacional del Comahue - CONICET, calle Buenos Aires 1400, Neuquén, 8300, Argentina.

3 Email de contacto: easoria@fcm.unc.edu.ar
} 


\section{Introducción}

El clorpirifos (O,O-dietil O-3,5,6-tricloro-2-piridil fosforotioato, CAS $n^{\circ}$ 2921-88-2) es uno de los insecticidas organofosforados más ampliamente utilizados en el control de plagas domésticas y agrícolas $^{1}$. Dicho uso aumenta las posibilidades de exposición tóxica de seres humanos ${ }^{2}$. Su mecanismo primario de toxicidad es la inhibición irreversible de la enzima acetilcolinesterasa, lo que produce desórdenes neurológicos ${ }^{3}$. No obstante, tiene otros múltiples mecanismos, cuyos blancos son las células inmunitarias, llevando a inmunotoxicidad ${ }^{4}$. Entre sus efectos, se encuentran inhibición enzimática, disrupción metabólica y apoptosis ${ }^{5}$. Así, la toxicidad causada por clorpirifos y el resto de los compuestos organofosforados conduce a inmunosupresión y pérdida de los mecanismos reguladores del sistema inmune, lo que induce procesos inflamatorios perjudiciales ${ }^{6}$.

Otro aspecto posiblemente involucrado en la inmunotoxicidad inducida por contaminantes es la modificación del balance redox en las células afectadas, siendo particularmente susceptibles los linfocitos $T^{7-8}$. En este sentido, el estrés oxidativo, la inducción de apoptosis y la inhibición de la blastogénesis han sido sugeridas como mecanismos subyacentes a este efecto deletéreo ${ }^{6-8}$. La susceptibilidad de esta estirpe puede ponerse de manifiesto valorando su capacidad de respuesta mitogénica a concanavalina $A$ in vitro, una lectina vegetal utilizada ampliamente para activar y proliferar a linfocitos $\mathrm{T}$ de manera policlonal y antígenoindependiente $e^{9-10}$.

Consecuentemente, aquellos compuestos con actividad redox son candidatos como moduladores de esta toxicidad $^{11}$. En este sentido, existen compuestos de origen vegetal con potencial protector y regulador de procesos celulares, siendo los extractos acuosos de las plantas fuentes de los mismos ${ }^{12-14}$. En el continente americano, numerosas plantas han sido propuestas para usos médicos ${ }^{15}$, identificándose la utilidad particular de alguna de ellas y sus extractos de infusiones ${ }^{12}$. Entre éstas, se incluyen Lantana grisebachii Stuck. (Verbenaceae), Aspidosperma quebracho-blanco Schltdl. (Apocynaceae), llex paraguariensis A. StHil. (Aquaifoliaceae) y Peumus boldus Molina (Monimiaceae), con potencial inmunológico ${ }^{7 ; 16-19}$. En función de lo antedicho, el objetivo de este trabajo fue evaluar la actividad moduladora de los extractos de estas plantas en esplenocitos (células inmunitarias ubicadas en el bazo provenientes de ratones Balb/c hembras) expuestos in vitro a clorpirifos, analizando viabilidad celular y marcadores redox.

\section{Materiales y métodos}

\section{Extractos vegetales}

Las muestras vegetales de L. grisebachii (LG), A. quebracho-blanco (AQ) fueron recolectadas durante el verano en la zona montañosa de la región fitogeográfica chaqueña del centro de Argentina (coordenadas GPS: $-31.28 /-64.44)^{20}$, contando con la autorización gubernamental correspondiente (Ministerio de Ciencia y Tecnología de Córdoba, Argentina). Los especímenes recolectados fueron identificados y depositados en el Herbario RIOC de la Universidad Nacional de Río Cuarto (Argentina). Por su parte, las muestras de I. paraguariensis (IP) y $P$. boldus (PB) provenían de cultivos orgánicos y fueron adquiridas comercialmente. Se dejaron secar muestras (partes aéreas) en ambiente seco, templado y oscuro para luego molerlas. Para obtener cada extracto, con 1 gramo de cada molienda se realizó una infusión con $5 \mathrm{~mL}$ de agua destilada inicialmente a $95^{\circ} \mathrm{C}$ permitiendo que se enfríe durante 1 hora (temperatura final: ambiente). Todo esto se llevó a cabo en oscuridad, bajo agitación constante y a temperatura ambiente ${ }^{21}$. Luego, fueron retirados los restos sólidos por filtración (poro de 0,2 $\mu \mathrm{m}$ ), cuyo sobrenadante estéril fue liofilizado al vacío a $-50^{\circ} \mathrm{C}$ durante 24 horas. El extracto seco remanente fue resuspendido en medio de cultivo constituyendo una solución madre de 100 $\mathrm{mg} / \mathrm{mL}$. La composición química de los extractos así obtenidos ha sido previamente determinada ${ }^{16}$.

\section{Esplenocitos y tratamiento in vitro}

Se utilizaron ratones hembras BALB/C endocriadas de 2 meses de edad, mantenidas bajo condiciones estándar de bioterio con alimentación (Gepsa SA, Argentina) e hidratación (Aguas Cordobesas SA, Argentina) ad libitum. Su manejo general $y$ sacrificio seguido por esplenectomía se llevaron a cabo de acuerdo a las normas procedimentales y éticas vigentes (Comité Institucional para el Cuidado y Uso de Animales de Laboratorio, Secretaría de Ciencia y Tecnología, Facultad de Ciencias Médicas, Universidad Nacional de Córdoba).

A partir de los bazos obtenidos por esplenectomía post mortem, se aislaron células mononucleares esplénicas (esplenocitos). Este procedimiento implicó colocar dichos órganos inmediatamente en medio RPMI-1640 completo, donde fueron disgregados mecánicamente y hemolizados químicamente (utilizando una solución hipotónica) a fin de obtener una suspensión celular, la cual fue lavada dos veces 
con medio de cultivo. Las células fueron mantenidas en medio RPMI-1640, completado con suero fetal bovino al $10 \%, 50 \mu \mathrm{M}$ de 2mercaptoetanol, $100 \mathrm{IU} / \mathrm{mL}$ de penicilina G sódica y $40 \mu \mathrm{g} / \mathrm{mL}$ de sulfato de gentamicina, en atmósfera de $5 \% \mathrm{CO}_{2}$ a $37^{\circ} \mathrm{C}^{22}$.

Para los ensayos correspondientes, se trataron durante 72 horas esplenocitos (1000 células/ $\mu \mathrm{L}$ ) no activados y activados con $5 \mu \mathrm{g} / \mathrm{mL}$ de concanavalina A (mitógeno $\mathrm{T}$ ). Los rangos de dosis empleados para los tratamientos fueron 0 $35 \mu \mathrm{g} / \mathrm{mL}$ de clorpirifos y $0-100 \mu \mathrm{g} / \mathrm{mL}$ de extracto vegetal.

Los químicos utilizados así como demás reactivos e insumos fueron provistos por SigmaAldrich Inc. (EE.UU.), mientras que el material plástico descartable para cultivo celular provino de ETC (Argentina).

\section{Viabilidad celular y citología}

La cantidad de células viables expuestas a los tratamientos fue valorada a través de su tinción con resazurina (concentración final en medio de cultivo: $0,05 \mathrm{mg} / \mathrm{mL}$ ), un colorante cuya captación y metabolización por parte de las mismas llevaba a cambio de su coloración tras 6 horas de cultivo $^{22}$. Así, la viabilidad celular se definió como porcentaje de densidad óptica respecto a control $(0 \mu \mathrm{g} / \mathrm{mL}$ de clorpirifos y $0 \mu \mathrm{g} / \mathrm{mL}$ de extracto, $\mathrm{C}=100 \%$ ) en cada pozo de una microplaca de 96 pozos a $600 \mathrm{~nm}$.

A través de citofluorescencia por marcación con yoduro de propidio $\left(10 \mu \mathrm{g} / \mathrm{mL}, 15\right.$ minutos, $37^{\circ} \mathrm{C}$, oscuridad) y análisis de microfotografías, se identificaron en rojo núcleos y fragmentos nucleares en células con compromiso de su viabilidad, ya que dicho fluoróforo es excluido activamente en células vivas. Se usó un video microscopio Zeiss Axiovert 135 con el programa de imágenes Axiovision (Alemania).

\section{Marcadores redox}

Se estudió la formación de peróxidos como marcadores de oxidación biológica de acuerdo a lo realizado anteriormente ${ }^{12 ; 23}$, tratando $10 \mu \mathrm{L}$ de suspensión celular con $100 \mu \mathrm{L}$ de cromógeno. Para hidroperóxidos, el cromógeno fue una solución acuosa de sorbitol $100 \mathrm{mM}$ y naranja de xilenol $0,125 \mathrm{mM}$ con un catalizador (sulfato amonio ferroso $25 \mathrm{mM}$ en ácido sulfúrico 2,5 M) en relación 100:1. Para lipoperóxidos, el cromógeno fue una solución metanólica de hidroxitolueno butilado $4 \mathrm{mM}$ y naranja de xilenol $0,125 \mathrm{mM}$ con el mismo catalizador. Luego de 30 minutos a temperatura ambiente, se midió absorbancia a $540 \mathrm{~nm}$.

Por otro lado, se cuantificó la actividad de $\mathrm{Y}$ - glutamiltranspeptidasa (GGT, EC 2.3.2.2, CD224), por su participación en la respuesta antioxidante y en el metabolismo de tóxicos ambientales $^{24}$. Se utilizó el método de Szasz basado en la cinética de la enzima en la reacción L-y-glutamil-3-carboxi-4-nitroanilida $(2,9 \mathrm{mM})+$ glicilglicina (100 mM) $\rightarrow$ L-y-glutamilglicilglicina + 5-amino-2-nitrobenzoato en buffer Tris $100 \mathrm{mM}$. Se mezclaron $10 \mu \mathrm{L}$ de suspensión celular tratada 30 minutos con Tritón $X-100$ al $0,1 \%$ y 100 de reactivos provistos en el kit $Y$-G-test $A A$ (Wiener Lab, Argentina). Se determinó la diferencia promedio por minuto de la absorbancia $(\Delta \mathrm{A} / \mathrm{min})$ a $405 \mathrm{~nm}$, valor que se multiplicaba por una constante $(\mathrm{UI} / \mathrm{L}=\Delta \mathrm{A} / \min \times 1158)$, en condiciones de velocidad inicial y en rangos de linealidad ${ }^{25}$.

Los estudios espectrofotométricos se realizaron con un multilector de microplacas GloMax®-Multi microplate multimode reader (Promega Corp., EE.UU.).

\section{Análisis estadístico}

Los datos fueron expresados como media \pm error estándar (EE) de $\geq$ cuatro experimentos separados realizados en triplicado. Se utilizaron modelos de ANOVA para evaluar el efecto de los tratamientos sobre la viabilidad celular, comparando las medias a través del test de Tukey para un $p<0,05$. Para analizar la correlación entre las variables de estudio se empleó la regresión de mínimos cuadrados parciales (análisis multivariado), expresando dicha correlación de manera gráfica ${ }^{26}$. Se utilizó el programa InfoStat versión 2012 (Grupo InfoStat, Argentina).

\section{Resultados:}

Se observó una reducción de la viabilidad celular dependiente de la concentración de clorpirifos, con una reducción significativa desde $8,75 \mu \mathrm{g} / \mathrm{mL}$ y alcanzando la $D_{50}$ a $35 \mu \mathrm{g} / \mathrm{mL}$, la cual se empleó en los ensayos ulteriores. A fin de establecer la causa de esta menor viabilidad, se halló que las células expuestas a clorpirifos tuvieron mayor captación de yoduro de propidio en campos microscópicos aumentados cien veces, encontrando figuras de fragmentación nuclear a una magnificación de cuatrocientas veces, compatible con figuras apoptóticas tanto en esplenocitos tratados o no con concanavalina A, conocido mitógeno linfocitario T (Figura 1).

Como se observa en la Figura 2, los extractos PB y LG no resultaron protectores frente a la concentración de clorpirifos empleada. Por su parte, aunque se mantuvo el efecto tóxico concentración-dependiente de clorpirifos, la 
adición del extracto IP previno significativamente la pérdida de viabilidad celular inducida por aquel $(p<0,05)$. En caso del extracto $A Q$, el descrito efecto fue anulado (curva de concentración sin inclinación), logrando niveles superiores de viabilidad $(p<0,05)$.

Al ser activos, los extractos IP y $A Q$ fueron ensayados nuevamente frente a clorpirifos en esplenocitos tratados con concanavalina A (mitógeno de linfocitos $\mathrm{T}$ ). Bajo estas condiciones, las células se mostraron susceptibles a clorpirifos de manera similar a cuando no estaban tratadas con el mitógeno, mientras que se redujo la actividad protectora de estos extractos, como se muestra en la Figura 3.
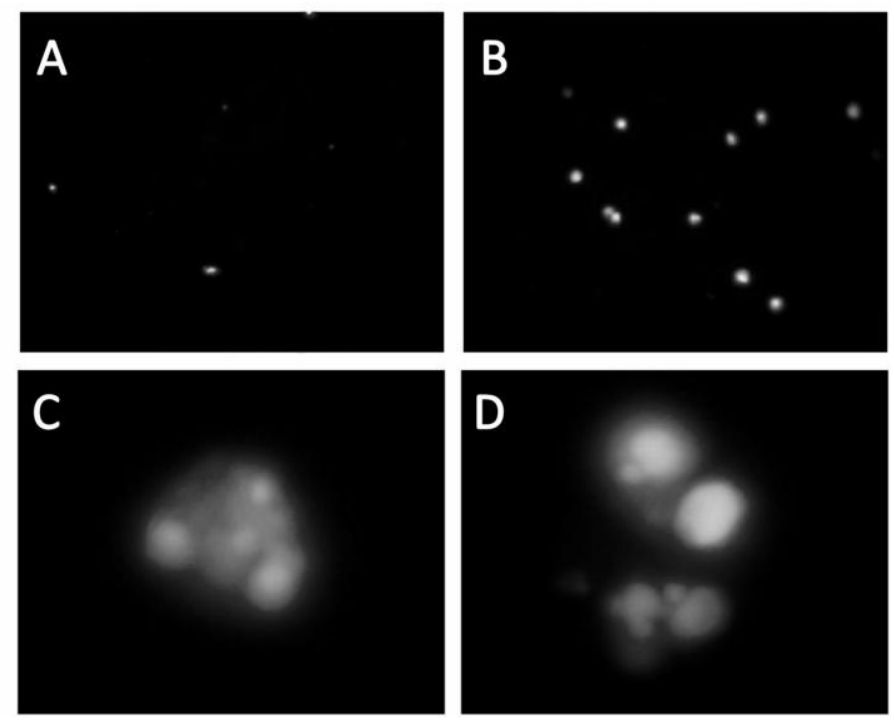

FIGURA 1. Muerte celular (marcación con yoduro de propidio) de linfocitos de ratones expuestos in vitro a clorpirifos (72 horas). Imágenes representativas de $n \geq 4$. Referencias: $A$ : esplenocitos estimulados con concanavalina $A$ con 0 $\mu \mathrm{g} / \mathrm{mL}$ de clorpirifos; B: esplenocitos estimulados con concanavalina $A$ con

$35 \mu \mathrm{g} / \mathrm{mL}$ de clorpirifos; C y D: figuras apoptóticas de esplenocitos estimulados con concanavalina A con $35 \mu \mathrm{g} / \mathrm{mL}$ de clorpirifos. Magnificación: A y B: $100 x, C$ y $D: 400 x$.

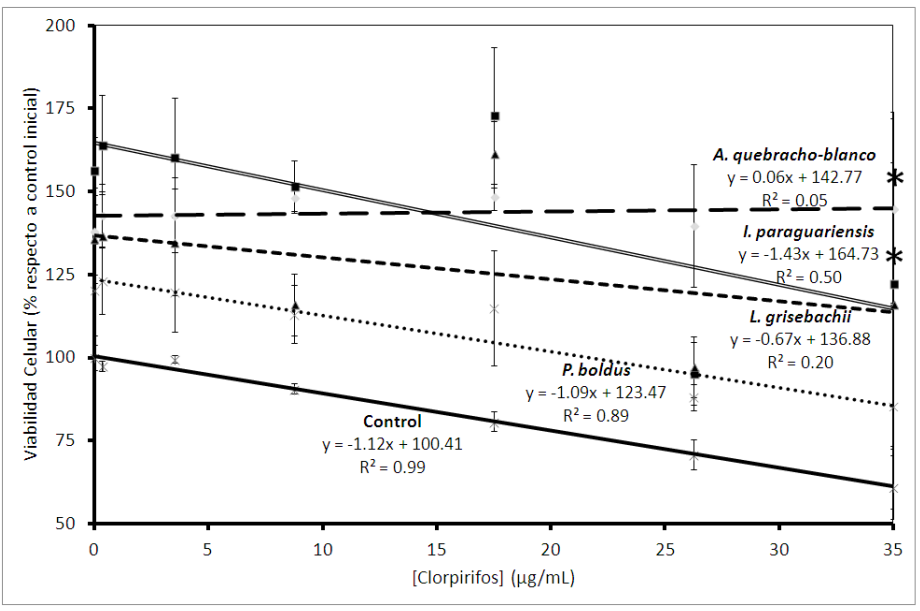

FIGURA 2. Viabilidad celular (medias \pm E.E., $n \geq 4$ ) de esplenocitos BALB/c expuestos in vitro a clorpirifos (0-35 $\mu \mathrm{g} / \mathrm{mL}, 72$ horas) y extractos infusivos (0$100 \mu \mathrm{g} / \mathrm{mL}, 72$ horas). * $\mathrm{p}<0,05$.

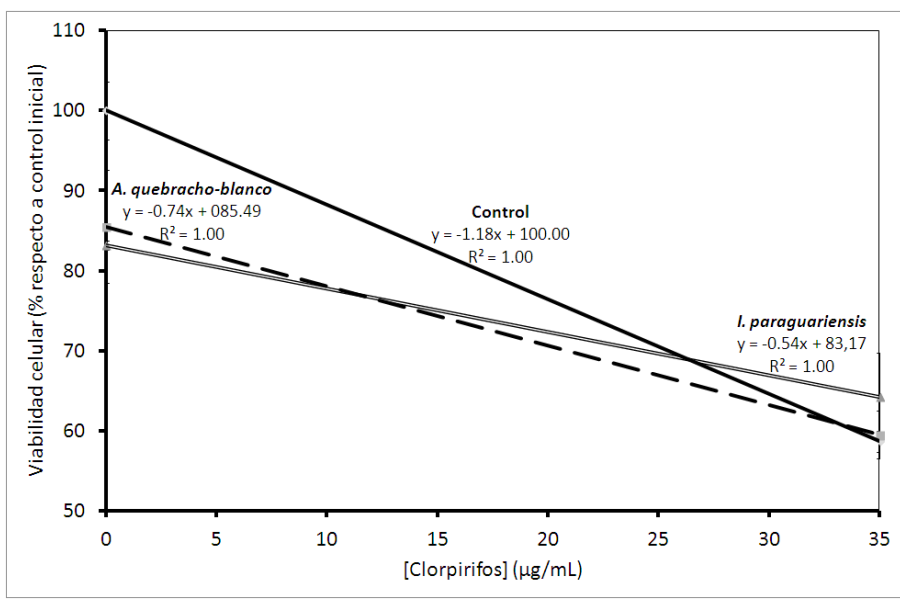

FIGURA 3. Viabilidad celular (medias \pm E.E., $n \geq 4$ ) de linfocitos de ratones hembras expuestos in vitro a clorpirifos $(0-35 \mu \mathrm{g} / \mathrm{mL}, 72$ horas) y fitoextractos infusivos (0-100 $\mu \mathrm{g} / \mathrm{mL}, 72$ horas). * $\mathrm{p}<0,05$.

A través de un modelo de regresión de mínimos cuadrados parciales mostrado en la Figura 4, se encontró que concentraciones crecientes de clorpirifos redujeron la viabilidad celular como se había visto previamente, mientras que concentraciones crecientes de concanavalina A la aumentaron, como se esperaba. Los extractos mostraron menores efectos sobre dicha respuesta. Clorpirifos se correlacionó con mayor actividad de y-glutamiltranspeptidasa y consecuentemente menor nivel de hidroperóxidos y lipoperóxidos. Ambos marcadores oxidativos tuvieron relación directa con la viabilidad celular y su inducción por concanavalina A. Ambos extractos aumentaban el nivel de lipoperóxidos, mientras reducían a yglutamiltranspeptidasa. En todos los casos, IP mostró mayor intensidad que $A Q$.

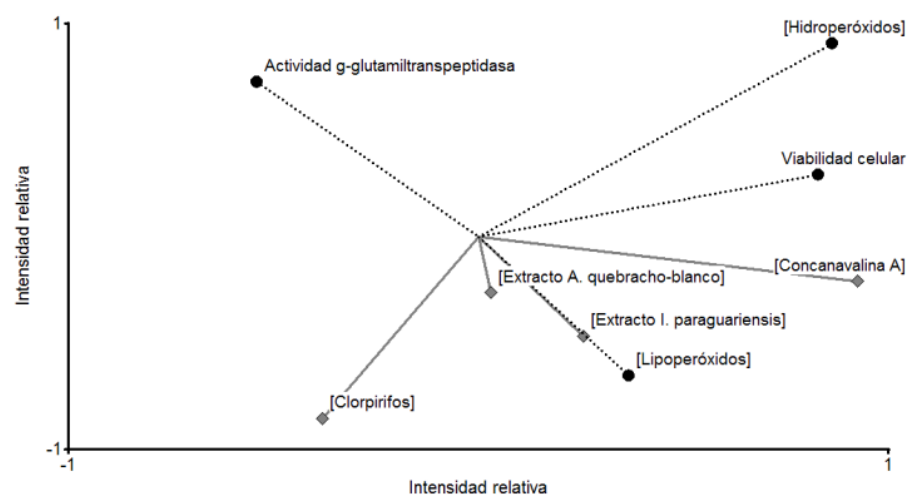

FIGURA 4. Correlación entre intensidades relativas de variables predictoras (en gris; concentración de concanavalina A -mitógeno, 0-5 $\mu \mathrm{g} / \mathrm{mL}$-, clorpirifos -tóxico, 0-35 $\mu \mathrm{g} / \mathrm{mL}$ - y extracto -I. paraguariensis o A. quebracho-blanco, 0-

$100 \mu \mathrm{g} / \mathrm{mL}-$ ) y respuestas celulares (en negro; nivel de viabilidad, hidroperóxidos, lipoperóxidos y $\mathrm{Y}$-glutamiltranspeptidasa), tras $\mathbf{7 2}$ horas de tratamiento in vitro de esplenocitos BALB/c ( $n \geq 8)$. 


\section{Discusión}

En concordancia con lo presentado en la introducción de este trabajo, se confirmó el efecto citotóxico de clorpirifos sobre esplenocitos, existiendo evidencia previa sobre esto, así como el rango de dosis, su efecto dosis dependiente y la $\mathrm{DL}_{50}{ }^{27 ; 28}$. Esta toxicidad se asoció con menor respuesta a concanavalina $A$, sugiriendo un compromiso de los linfocitos $T$, ya que son los esplenocitos capaces de responder a dicho antígeno policlonal mitogénico. Esto ha sido propuesto por otros autores, incluyendo la inducción de apoptosis en esta estirpe celular ${ }^{27 ; 6}$. PB contiene fitoquímicos antioxidantes capaces de proteger a hepatocitos y eritrocitos frente a estrés oxidativo ${ }^{17 ; 19}$. En este sentido, clorpirifos no indujo peroxidación, por lo tanto PB no fue efectivo. Asimismo, LG, reportado como antioxidante y protector de esplenocitos expuestos a otro contaminante $e^{7 ; 12}$, tampoco fue capaz de contrarrestar la toxicidad de clorpirifos.

El efecto protector de IP sobre esplenocitos expuestos a clorpirifos puede indicar el contenido de compuestos bioactivos, tal como sugieren otros autores ${ }^{18}$, incluyendo su mayor nivel de polifenoles y flavonoides ${ }^{16}$. Esto se contrapone con hallazgos sobre derivados provenientes de otras especies vegetales, los cuales son capaces de reducir la activación linfocitaria ${ }^{29}$. Por otro lado, la mayor viabilidad de esplenocitos tratados con $A Q$ sugieren una actividad promotora sobre dichas células. En este sentido, se halló que dicho extracto y sus compuestos presentan actividad inmunoestimulante ${ }^{30}$, así como puede contrarrestar al clorpirifos por un potencial efecto quelante, dada la ausencia hallada de respuesta dosis-dependiente. Hasta donde se conoce, es la primera vez que se identifica un potencial inmunoprotector frente a clorpirifos por parte de los extractos vegetales estudiados.

Dada la reducción de la capacidad protectora de IP y $A Q$ en células tratadas con concanavalina $A$, se infiere que dicha capacidad es relevante en los esplenocitos no $T$, siendo éstos (ej.: linfocitos B) más resistentes a la toxicidad por clorpirifos ${ }^{31}$. Además, es necesario tener en cuenta que las células en mitosis, inducible por concanavalina A, son más sensibles al efecto de agentes deletéreos $^{32}$, y que la estirpe $\mathrm{T}$ muestra alta susceptibilidad dichos agentes ${ }^{33 ; 7}$.

$\mathrm{Si}$ bien se ha reportado el efecto oxidativo de clorpirifos $^{34 ; 11}$, en este trabajo se asoció negativamente con el nivel de hidroperóxidos y lipoperóxidos, como consecuencia de su asociación positiva con la actividad de GGT, la cual forma parte de la respuesta antioxidante de las células ${ }^{24 ; 25}$. Luego, la asociación hallada en esplenocitos entre su viabilidad y actividad de
GGT es concordante como hallazgos en otros estudios $^{35,36}$. En este contexto, tomando a esta enzima como marcadora de respuesta a clorpirifos, se encontró que los extractos $A Q$ y principalmente IP antagonizaron su actividad. En este sentido, se ha descrito la inhibición de GGT por estos extractos en diferentes tejidos de ratones hembras ${ }^{16}$.

\section{Conclusión}

El presente trabajo muestra que los extractos de Ilex paraguariensis y Aspidosperma quebrachoblanco fueron capaces de proteger in vitro a esplenocitos expuestos al agroquímico clorpirifos, si bien son necesarios estudios adicionales para avanzar en el análisis de sus fitoquímicos bioactivos. No obstante, dicha inmunoprotección depende de las características propias de cada estirpe celular, mostrando mayor susceptibilidad al tóxico aquellas células inducibles por concanavalina A (ej.: linfocito T). Esto promueve la investigación acerca del compromiso por clorpirifos de la inmunidad celular, llevando a inmunodepresión y disfunción de alto impacto sanitario para seres humanos.

\section{Agradecimientos}

El financiamiento provino de la Universidad Nacional de Córdoba y de la Universidad Nacional del Comahue. El trabajo de A.V. Scotta fue apoyado por una beca del PROMED (Ministerio de Educación de la Nación). No existen conflictos de intereses.

\section{Bibliografía}

1- Lantieri MJ, Butinof M, Fernández R, Stimolo MI, Blanco M, Diaz MP. Work Practices, Exposure Assessment and Geographical Analysis of Pesticide Applicators in Argentina. In: Stoytcheva M. Pesticides in the modern world - effects of pesticides exposure. Rijeka: Intech Open Access Publisher. 2011, pp 115-38.

2- Eaton $D L$, Daroff $R B$, Autrup $H$, Bridges $J$, Buffler $P$, Costa LG, Coyle J, McKhann G, Mobley WC, Nadel L, Neubert $D$, Schulte-Hermann R, Spencer PS. Review of the toxicology of chlorpyrifos with an emphasis on human exposure and neurodevelopment.Crit Rev Toxicol. 2008;38 Supp/ 2:1-125.

3- Lee YS, Lewis JA, Ippolito DL, Hussainzada N, Lein PJ, Jackson DA, Stallings JD. Repeated exposure to neurotoxic levels of chlorpyrifos alters hippocampal expression of neurotrophins and neuropeptides. Toxicology. 2016 Jan 18;340:53-62.

4- Jowzi N, Rahimifard M, Navaei-Nigjeh $M$, Baeeri $M$, Darvishi B, Rezvanfar MA, Abdollahi M. Reduction of chlorpyrifos-induced toxicity in human lymphocytes by selected phosphodiesterase inhibitors. Pestic Biochem Physiol. 2016 Mar;128:57-62.

5- Noworyta-Głowacka J, Beresińska M, Bańkowski $R$, Wiadrowska B, Siennicka J, Ludwicki JK. Effect of chlorpyrifos on the profile of subpopulations 
immunocompetent cells $B, T$ and NK in in vivo model. Rocz Panstw Zakl Hig. 2014;65(4):311-6.

6- Li Q, Kobayashi M, Kawada T. Chlorpyrifos induces apoptosis in human $T$ cells. Toxicology. 2009 Jan 8;255(1-2):53-7.

7- Soria EA, Quiroga PL, Albrecht C, Ramos Elizagaray SI, Cantero JJ, Bongiovanni GA. Development of an Antioxidant Phytoextract of Lantana grisebachii with Lymphoprotective Activity against In Vitro Arsenic Toxicity. Adv Pharmacol Sci. 2014; 2014:416761.

8- Singh AK, Parashar A, Singh AK, Singh R. Prenatal/juvenile chlorpyrifos exposure associated with immunotoxicity in adulthood in Swiss albino mice. $J$ Immunotoxicol. 2013 Apr-Jun;10(2):141-9.

9- Palacios $R$. Concanavalin A triggers $T$ lymphocytes by directly interacting with their receptors for activation. $J$ Immunol. 1982 Jan;128(1):337-42.

10- Ando Y, Yasuoka $C$, Mishima T, Ikematsu $T$, Uede $T$, Matsunaga $T$, Inobe M. Concanavalin A-mediated $T$ cell proliferation is regulated by herpes virus entry mediator costimulatory molecule. In Vitro Cell Dev Biol Anim. 2014 Apr;50(4):313-20.

11- Heydary V, Navaei-Nigjeh $M$, Rahimifard $M$, Mohammadirad A, Baeeri M, Abdollahi M. Biochemical and molecular evidences on the protection by magnesium oxide nanoparticles of chlorpyrifos-induced apoptosis in human lymphocytes. J Res Med Sci. 2015 Nov;20(11):1021-31.

12- Soria EA, Goleniowski ME, Cantero JJ, Bongiovanni GA. Antioxidant activity of different extracts of Argentinian medicinal plants against arsenic-induced toxicity in renal cells. Hum Exp Toxicol. 2008 Apr;27(4):341-6. doi: 10.1177/0960327108092192.

13- Cuevas A, Saavedra $N$, Salazar LA, Abdalla DS. Modulation of immune function by polyphenols: possible contribution of epigenetic factors. Nutrients. 2013 Jun 28;5(7):2314-32. doi: 10.3390/nu5072314.

14- Surh YJ. Xenohormesis mechanisms underlying chemopreventive effects of some dietary phytochemicals. Ann N Y Acad Sci. 2011 Jul;1229:1-6. doi: 10.1111/j.1749-6632.2011.06097.

15- Goleniowski ME, Bongiovanni GA, Palacio L, Nuñez CO, Cantero JJ. Medicinal plants from the "Sierra de Comechingones", Argentina. J Ethnopharmacol. 2006 Oct 11;107(3):324-41.

16- Canalis AM, Cittadini MC, Albrecht C, Soria EA. In vivo redox effects of Aspidosperma quebracho-blanco Schltdl., Lantana grisebachii Stuck and Ilex paraguariensis A. St.-Hil. on blood, thymus and spleen of mice. Indian J Exp Biol. 2014 Sep;52(9):882-9.

17- Muthna D, Cmielova J, Tomsik P, Rezacova M. Boldine and related aporphines: from antioxidant to antiproliferative properties. Nat Prod Commun. 2013 Dec;8(12):1797-800.

18- Bracesco N, Sanchez AG, Contreras V, Menini T, Gugliucci $A$. Recent advances on Ilex paraguariensis research: minireview. J Ethnopharmacol. $2011 \mathrm{Jul}$ 14;136(3):378-84. doi: 10.1016/j.jep.2010.06.032.

19- O'Brien P, Carrasco-Pozo C, Speisky H. Boldine and its antioxidant or health-promoting properties. Chem Biol Interact. 2006;159:1-17.

20- Cabrera AL. Regiones fitogeográficas argentinas. En: Enciclopedia Argentina de Agricultura y Jardinería. Buenos Aires: Editorial ACME SA. 1976, pp 85.

21- Borneo R, León AE, Aguirre A, Ribotta P, Cantero JJ. Antioxidant capacity of medicinal plants from the Province of Cordoba (Argentina) and their in vitro testing in a model food system. Food Chem. 2009;112:664-70.

22- Strotmann UJ, Butz B, Bias WR. The dehydrogenase assay with resazurin: Practical performance as a monitoring system and $\mathrm{pH}$-dependent toxicity of phenolic compounds. Ecotoxicol Environ Saf. 1993;25:79-89.
23- Erel O. A new automated colorimetric method for measuring total oxidant status. Clin Biochem. 2005;38:1103-11.

24- Zhang H, Forman HJ. Redox regulation of gammaglutamyl transpeptidase. Am J Respir Cell Mol Biol. 2009;41:509-15.

25- Quiroga A, Quiroga PL, Martínez E, Soria EA, Valentich $M A$. Anti-breast cancer activity of curcumin on the human oxidation-resistant cells ZR-75-1 with gammaglutamyltranspeptidase inhibition. J Exp Ther Oncol. 2010;8:261-6.

26- Sæbø, S., Almøy, T., Flatberg, A., Aastveit, A.H., Martens, H., 2008. LPLS-regression: a method for prediction and classification under the influence of background information on predictor variables. Chemometr Intell Lab, 91, 121-132.

27- Nakadai $A, L i$ Q, Kawada T. Chlorpyrifos induces apoptosis in human monocyte cell line U937. Toxicology. 2006;224:202-9.

28- Vindas R, Ortiz F, Ramírez, Cuenca. Genotoxicidad de tres plaguicidas utilizados en la actividad bananera de Costa Rica. Rev Biol Trop. 2004; 52:601-9.

29- Nani A, Belarbi M, Ksouri-Megdiche W, Abdoul-Azize S, Benammar $C$, Ghiringhelli $F$, Hichami A, Khan NA. Effects of polyphenols and lipids from Pennisetum glaucum grains on T-cell activation: modulation of $\mathrm{Ca}(2+)$ and ERK1/ERK2 signaling. BMC Complement Altern Med. 2015 Dec 1;15:426.

30- Akbay P, Basaran AA, Undeger U, Basaran N. In vitro immunomodulatory activity of flavonoid glycosides from Urtica dioica L.Phytother Res. 2003 Jan;17(1):34-7.

31- Scotta AV. Modulación in vitro de la linfotoxicidad oxidativa de clorpirifos por extractos acuosos de plantas nativas argentinas. Tesina de grado, Medicina. Facultad de Ciencias Médicas. Universidad Nacional de Córdoba. 2014.

32- Kocaman AY, Topaktaş $M$. The in vitro genotoxic effects of a commercial formulation of alpha-cypermethrin in human peripheral blood lymphocytes. Environ Mol Mutagen. 2009;50:27-36.

33- Biró A, Fodor Z, Major J, Tompa A. Immunotoxicity monitoring of hospital staff occupationally exposed to cytostatic drugs. Pathol Oncol Res. 2011;17:301-8.

34- Abolaji AO, Awogbindin IO, Adedara IA, Farombi EO. Insecticide chlorpyrifos and fungicide carbendazim, common food contaminants mixture, induce hepatic, renal, and splenic oxidative damage in female rats. Hum Exp Toxicol. 2016 Jun 6.

35- Täger M, Ittenson A, Franke A, Frey A, Gassen HG, Ansorge S. gamma-Glutamyl transpeptidase-cellular expression in populations of normal human mononuclear cells and patients suffering from leukemias. Ann Hematol. 1995;70:237-42.

36- Carlisle ML, King MR, Karp DR. Gamma-glutamyl transpeptidase activity alters the $T$ cell response to oxidative stress and Fas-induced apoptosis. Int Immunol. 2003;15:17-27. 